Article

\title{
Development of Intracorporeal Differentiation of Stem Cells to Induce One-Step Mastoid Bone Reconstruction during Otitis Media Surgeries
}

\author{
Sung-Hee Park ${ }^{1,+}$, Hantai Kim ${ }^{1,+}{ }^{\mathbb{D}}$, Yun Yeong Lee ${ }^{1} \mathbb{D}$, Yeon Ju Kim ${ }^{1}$, Jeong Hun Jang ${ }^{1}$, Oak-Sung Choo ${ }^{2, *}$ and \\ Yun-Hoon Choung ${ }^{1, *}$ \\ 1 Department of Otolaryngology, Ajou University School of Medicine, Suwon 16499, Korea; \\ soyclara99@naver.com (S.-H.P.); noto.hantai@gmail.com (H.K.); seven260@ajou.ac.kr (Y.Y.L.); \\ yeonju0130@naver.com (Y.J.K.); jhj@ajou.ac.kr (J.H.J.) \\ 2 Department of Otorhinolaryngology, Eulji University School of Medicine, Uijeongbu 11759, Korea \\ * Correspondence: oschoo1202@gmail.com (O.-S.C.); yhc@ajou.ac.kr (Y.-H.C.) \\ $\dagger$ These authors contributed equally to this work.
}

check for

updates

Citation: Park, S.-H.; Kim, H.; Lee, Y.Y.; Kim, Y.J.; Jang, J.H.; Choo, O.-S.; Choung, Y.-H. Development of Intracorporeal Differentiation of Stem Cells to Induce One-Step Mastoid Bone Reconstruction during Otitis Media Surgeries. Polymers 2022, 14, 877. https://doi.org/10.3390/ polym 14050877

Academic Editor: Antonino Morabito

Received: 24 January 2022 Accepted: 20 February 2022 Published: 23 February 2022

Publisher's Note: MDPI stays neutral with regard to jurisdictional claims in published maps and institutional affiliations.

Copyright: (C) 2022 by the authors. Licensee MDPI, Basel, Switzerland. This article is an open access article distributed under the terms and conditions of the Creative Commons Attribution (CC BY) license (https:// creativecommons.org/licenses/by/ $4.0 /)$.

\begin{abstract}
Mastoidectomy is a surgical procedure for the treatment of chronic otitis media. This study investigated the ability of rat stromal vascular fraction cells (rSVF) in combination with polycaprolactone (PCL) scaffolds and osteogenic differentiation-enhancing blood products to promote the regeneration of mastoid bone defect. Twenty male Sprague Dawley rats were randomly divided according to obliteration materials: (1) control, (2) PCL scaffold only, (3) rSVFs + PCL, (4) rSVFs + PCL + platelet-rich plasma, and (5) rSVFs + PCL + whole plasma (WP). At 7 months after transplantation, the rSVFs + PCL + WP group showed remarkable new bone formation in the mastoid. These results indicate that SVFs, PCL scaffolds, and blood products accelerate bone regeneration for mastoid reconstruction. Autologous SVF cells with PCL scaffolds and autologous blood products are promising composites for mastoid reconstruction which can be easily harvested after mastoidectomy. With this approach, the reconstruction of mastoid bone defects can be performed right after mastoidectomy as a one-step procedure which can offer efficiency in the clinical field.
\end{abstract}

Keywords: mastoidectomy; osteogenesis; stromal vascular fraction cells; polycaprolactone (PCL) scaffold; autologous growth factor

\section{Introduction}

The management of middle ear disease occasionally requires a canal wall-down mastoidectomy. Mastoidectomy is a surgical procedure to remove an infected mastoid bone and air cells that have a honeycomb-like framework. The inner surfaces are also covered with mucosa resulting from chronic ear diseases such as otitis media and mastoiditis. This structure is associated with gas exchange function and pressure regulation of the middle ear [1-3]. Although this surgical procedure is indispensable for the eradication of chronic ear diseases, it has a common problem of altering the anatomy and physiology of the middle ear which can cause repetitive chronic infections, dizziness, granulation tissue formation, and the accumulation of keratin debris [4]. Furthermore, open cavity mastoidectomy may also cause difficulty in fitting a hearing aid as well as vertigo attacks following pressure or temperature changes and loss of the ability to self-clear the external acoustic canal [5]. To reduce open cavity problems, mastoid obliteration along with the reconstruction of the posterior wall of the external auditory canal and air cells has been attempted [6-9].

Autologous grafts are preferred over alloplastic and biosynthetic materials because of biological safety, cost effectiveness, and the provision of an ideal construct supplying osteoinductive growth factor. However, these autologous tissues also have limitations such as insufficient amount, restricted donor site defects, and unpredictable resorption 
after surgery [10,11]. To overcome these problems, we used uncultured stromal vascular fractions (SVFs), which can be transplanted without further in vitro selection or expansion steps; possess the multiple capacity to differentiate into adipose osteoblasts, adipocytes, chondrocytes, and myocytes rapidly, as compared to bone marrow stem cells; and have the advantage of providing a non-invasive harvest approach [12]. Recent evidence showed that an SVF also induced osteogenic differentiation with a hydroxyapatite scaffold [13] and there was a minor difference in kinetics and phenotype of differentiation between freshly isolated adipose stem cells (ASCs) and cultured ASCs [14]. Stromal cells from adipose tissue have a higher proliferative rate, autocrine production of growth factors, and immunomodulatory effects to reduce the immune response for tissue regeneration [15]. Moreover, SVF cells cultured within 3D ceramic scaffolds induced osteogenesis after subcutaneous implantation in vivo [16]. The clinical application of free fat isolated from liposuction aspirates shows an alternative strategy to soft tissue augmentation surgery to tissue reconstruction [17]. In fact, SVF enrichment was proven to stimulate the secretion of growth factors encouraging angiogenesis, as well as pericytes and endothelial cells, contained in the stromal vascular fraction $[18,19]$.

Polycaprolactone (PCL) nanofiber scaffold is a biodegradable polyester material, which has been widely employed to support adhesion, proliferation, and acceleration of osteogenic differentiation in MSC-based cell regenerative therapy for treating bone impairment [20-23]. PCL nanofiber scaffold has also been exploited in several kinds of adhesion barriers, implants, and drug delivery devices that have been approved by the FDA. Recent in vivo studies evidently showed that the molecular weight of explanted PCL material in rabbit calvaria had decreased by $63 \%$ in 2 years [24] and implanted PCL material in the dorsal skin of rat was metabolized by unknown process which ultimately excreted it from the body and this was detected at day 15 [25].

The utilization of autologous growth factors derived from blood can represent an effective support in tissue regeneration due to their ability to stimulate cell proliferation, differentiation, and neo-angiogenesis, and was investigated for clinical use [26]. The widely studied platelet-rich plasma (PRP), obtained by blood centrifugation, is widely applied in clinical areas such as orthopedics, ophthalmology, and otorhinolaryngology. PRP has various growth factors, including fibroblast growth factor, epidermal growth factor, vascular endothelial growth factor, platelet-derived growth factor, transforming growth factor- $\beta$, and insulin-like growth factor [27]. Despite the focused use of PRP, the efficacy of PRP remains under debate because of the lack of consensus in the optimal preparation condition for tissue regeneration [28]. The clear effect of PRP on osteogenic differentiation remains to be elucidated and some studies have reported conflicting results about the effect of PRP on osteogenesis [29,30].

Previous studies have often compared the abilities and functions of PRP and plateletpoor plasma (PPP) [27], but rarely compared these with whole plasma (WP), a bioproduct obtained from pretreatment. Given the unstandardized protocol and the inconsistent results of PRP in clinical applications, WP is expected to be a stable clinical material as it escapes the risk of high leukocyte involvement and the excessive secretion of pro-inflammatory cytokines, and is obtained by a simple one-step manipulation.

In this study, we investigated the biological effects of uncultured autologous adipose tissue-derived SVFs and blood products on a PCL scaffold on osteogenic differentiation. Through this approach, we tried to develop a technique that can be performed in a convenient and efficient one-step procedure immediately after mastoid resection by confirming the anatomical and functional reconstruction of mastoid bone defect.

\section{Materials and Methods}

\subsection{Fabrication of the PCL Scaffold}

The PCL scaffolds were fabricated via a solvent-casting/salt-leaching technique. Briefly, PCL (Sigma-Aldrich, St. Louis, MO, USA) was dissolved in tetrahydrofuran $(10 \%$ $v / v$, Sigma-Aldrich, St. Louis, MO, USA). $\mathrm{NaCl}$ (Amresco, Solon, OH, USA) was added to 
the PCL solution and the suspension was continuously stirred until the viscosity increased. The final mixture was cast into cylindrical acryl molds and dried in a fume hood for $24 \mathrm{~h}$ after which the solvent was completely evaporated. Finally, the scaffolds were immersed in distilled water for $2 \mathrm{~h}$ to remove $\mathrm{NaCl}$ and then dried for $24 \mathrm{~h}$.

\section{2. rSVF Cells Isolation and Culture}

SVFs were isolated from Sprague Dawley (SD) male rats (7 weeks) according to previous reports [31,32]. Briefly, $200 \mathrm{~g}$ of fat from subcutaneous adipose tissue was removed under sterile conditions, washed with PBS containing 1\% $v / v$ penicillin/streptomycin, and finely minced with blades. The chopped fat was incubated with low-glucose Dulbecco's modified Eagle's medium (DMEM), which contained $0.075 \%$ collagenase type I (SigmaAldrich, St. Louis, MO, USA), at $37^{\circ} \mathrm{C}$ for $30-60 \mathrm{~min}$. The solution was then neutralized with low-glucose Dulbecco's modified Eagle's medium (DMEM) containing 10\% fetal bovine serum (FBS) and filtered through $100 \mu$ m nylon mesh strainers. The high density fraction was then sedimented after centrifugation at $1300 \times \mathrm{g}$ for $3 \mathrm{~min}$. The pellet was resuspended in DMEM, which was then cultured in a humidified incubator under $37^{\circ} \mathrm{C}$ in an atmosphere containing 5\% $\mathrm{CO}_{2}$ in basal media (DMEM, 10\% FBS, 1\% v/v penicillin/streptomycin). Culture media were changed every 2 days before use. Upon reaching about $80 \%$ confluence, the cells were trypsinized and replated at $1.0 \times 10^{5}$ cells/60 millimeters-squared dish for further study. Cells from the first passage were used individually.

\subsection{Fluorescent-Activated Cell-Sorting Analysis}

Day 1 and 6 of passage 0 rSVF cells were detached with $0.25 \%$ trypsin/EDTA (Corning) and centrifuged at $1300 \mathrm{rpm}$ for $3 \mathrm{~min}$. The supernatant was discarded and the rSVF cells were washed using PBS, centrifuged at $1300 \mathrm{rpm}$ for $3 \mathrm{~min}$, and the pellet resuspended in sterile FACS buffer (PBS, 1\% FBS) containing fluorescein isothiocyanate (FITC) conjugated CD29 and CD90 (BioLegend, San Diego, CA, USA) for $1 \mathrm{~h}$ at $4{ }^{\circ} \mathrm{C}$. The analysis was carried out with a BD FACSAriaTM III (BD Biosciences, San Jose, CA, USA).

\subsection{Preparation of Rat Blood Products}

Blood products were prepared from SD male rats (7 weeks) used for SVF isolation. In brief, whole blood was drawn, via puncture of the heart, into a syringe. The whole blood sample from SD rats was initially collected into a $5.4 \mathrm{mg}$ (spray-dried) K2 EDTA tube (BD Vacutainer $^{\circledR}$, Becton Dickinson, NK, USA) which also functioned as an anticoagulant. The whole blood sample was centrifuged for $25 \mathrm{~min}$ at $400 \times g$ at $4{ }^{\circ} \mathrm{C}$ to separate the plasma containing the platelets from the red blood cells. After the formation of three layers, only the WP containing buffy coat was transferred to a new tube and mixed well. The $10 \%$ volume of the whole blood was transferred to the new tube and the rest of the whole plasma was further centrifuged for $15 \mathrm{~min}$ at $800 \times \mathrm{g}$ at $4{ }^{\circ} \mathrm{C}$ to separate the platelets. Platelet-poor plasma, which comprised $10 \%$ of the volume of the whole blood, was drawn off the top and PRP, which comprised $10 \%$ of the volume of the whole blood, was drawn off the bottom. Then, platelets were activated by $10 \%(v / v) \mathrm{CaCl}_{2}$ for $1 \mathrm{~h}$ at $37^{\circ} \mathrm{C}$ and $12 \mathrm{~h}$ at $4{ }^{\circ} \mathrm{C}$ to induce the exocytosis of $\alpha$-granules and growth factors. After clot formation, blood products were centrifuged at $3000 \times g$ for $20 \mathrm{~min}$ and the supernatant was aspirated and then filtered through $0.22 \mu \mathrm{m}$ filters.

\subsection{Osteogenic Differentiation}

To induce osteogenic differentiation, the first passage rSVF cells were seeded into a $60 \mathrm{~mm}^{2}$ dish at a density of $1.0 \times 10^{5}$ cells and incubated at $37^{\circ} \mathrm{C}$ in an atmosphere containing $5 \% \mathrm{CO}_{2}$. Subsequent to adding the cell suspension with osteogenic differentiation media containing low-glucose DMEM (10\% v/v FBS, $1 \% v / v$ penicillin/streptomycin) supplemented with L-ascorbic acid 2-phosphate $(50.0 \mu \mathrm{M}$ final), dexamethasone $(0.1 \mu \mathrm{M}$ final) and $\beta$-glycerophosphate $(10.0 \mathrm{mM}$ final) to the cell culture dish, the culture media were replaced every $2-3$ days. 


\subsection{Alizarin Red S Staining}

The passage $1 \mathrm{SVFs}$ were cultured in each blood production medium with low-glucose DMEM for 21 days. Then, the cells in each treatment group were stained with Alizarin Red S solution (Sigma-Aldrich, St. Louis, MO, USA) according to the manufacturer's instructions to determine the presence of calcium crystal deposition, an indicator of osteogenic differentiation. This is an early stage marker of matrix mineralization, an essential step toward the formation of calcified extracellular matrix associated with bone. At each analysis, SVFs were fixed in $4 \%$ paraformaldehyde for $30 \mathrm{~min}$, followed by normal saline washing and staining with $2 \%$ Alizarin Red S (pH 4.2) for $10 \mathrm{~min}$ at room temperature. Next, $20 \%$ methanol $10 \%$ acetic acid solution was added to the stained rSVFs, which were then left for $30 \mathrm{~min}$. The mineral content was determined by absorbance values at $450 \mathrm{~nm}$ using a microplate reader [33].

\subsection{In Vivo Animal Study}

Twenty SD male rats (7 weeks, $200-250$ g) were used in this study. Ajou University School of Medicine-Institutional Animal Care and Use Committee (IACUC number, 20190049) approved the surgical procedures in accordance with the guidelines regarding the care and use of animals for experimental procedures. All efforts were made to minimize the number of animals used and their suffering. The animal models for mastoidectomy followed our previous study [34]. Briefly, SD rats were anesthetized with an intraperitoneal injection of Zoletil 50 (0.1 cc/100 g; Virvac Laboratories, Carros, France) and 2\% Rompun $(0.2 \mathrm{cc} / 100 \mathrm{~g}$; Bayer Korea, Ansan, Korea). For mastoid bulla defects, the anterior midline neck skin was incised using a scalpel to expose both sides of the bulla (anterior approach), and $3 \times 3 \mathrm{~mm}$ holes were made using a straight pick. Then, 3D PCL scaffold was placed in the mastoid cavity in the PCL group. Fat $(50 \mathrm{mg})$ was transplanted directly into the $5 \mathrm{~mm}$ diameter of the PCL scaffolds with $50 \mu \mathrm{L}$ of normal saline and placed in the bulla cavity in the PCL + fat (PF) group. The remaining groups were transplanted with $50 \mu \mathrm{L}$ of blood product components such as PRP and WP, respectively (Figure 1).

A

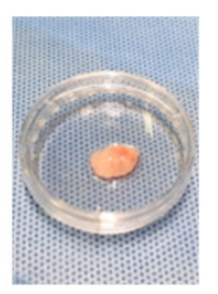

B

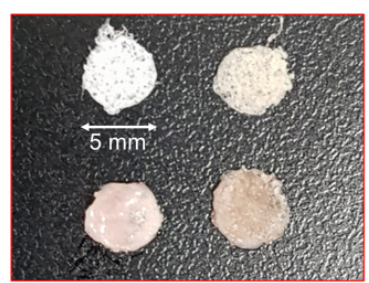

C

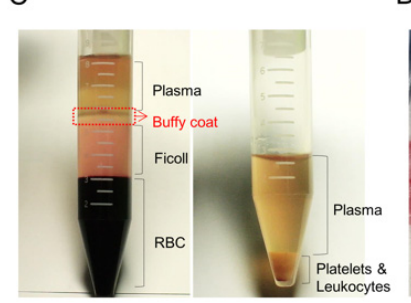

$\mathrm{D}$

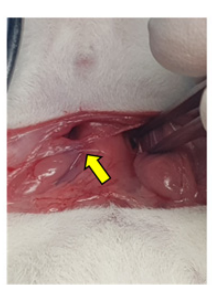

E

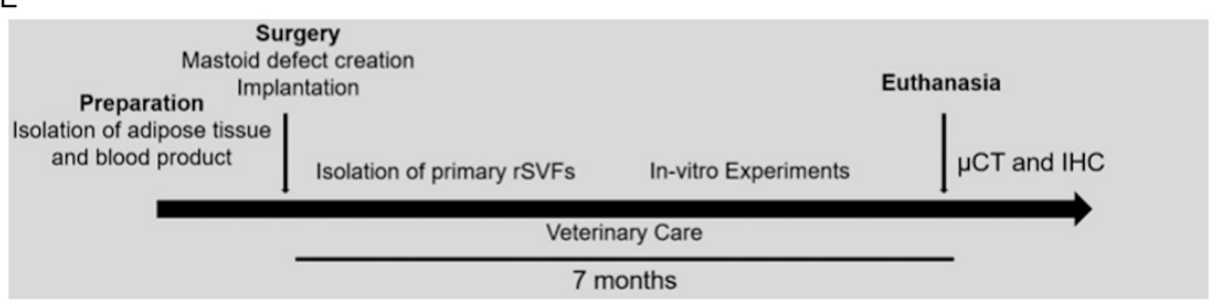

Figure 1. In vivo study design. The experimental composites included (A) uncultured stromal cells (fat) in a $35 \mathrm{~mm}$ dish, (B) PCL scaffold with blood products, and (C) blood products for bone reconstruction in mastoid bulla ( $15 \mathrm{~mL}$ conical tube). (D) Surgical procedure was performed with an anterior auricular incision with the yellow arrow indicating mastoid bulla defects. (E) The overall study schedule of the experiment for mastoid regeneration.

We allocated $4 \mathrm{SD}$ rats to each group. However, one in the control group and two in the PFP group died before the evaluations at 7 months. Thus, final radiologic (micro-CT) and histological (immunohistochemistry) studies were performed on a total of 17 rats. 


\subsection{Radiologic Evaluation}

The newly formed bone was analyzed after imaging the bulla samples using micro-CT (SkyScan 1076; SkyScan, Kontich, Belgium), as in previous studies. Briefly, a $35 \mathrm{kV}$ source voltage and a $170 \mu \mathrm{A}$ source current were used, and 569 images per bulla sample were obtained with an image pixel size of $36.44 \mu \mathrm{m}$ with a $1.0 \mathrm{~mm}$ aluminum filter. Images obtained as individual sections were modeled in 3D using 3D image-processing software (MIMICS 16.0; Materialize Mimics, Leuven, Belgium). The newly formed bone was identified using the bone mineral content within each bulla. Then, the bone volume and the bone/total volume were calculated from the micro images for quantitative comparison between groups.

\subsection{Histological Study}

After 7 months, temporal bones were fixed with $4 \%$ paraformaldehyde and kept overnight at $4{ }^{\circ} \mathrm{C}$. After decalcification with Calci-Clear Rapid solution (National Diagnostics, Hs-105) for 10 days, temporal bones were embedded in paraffin and 10 micrometersthick sections cut, deparaffinized, rehydrated, and then subjected to modified antigenretrieval using pepsin and non-specific peroxidase blocking. Some specimens were stained with hematoxylin (Youngdong Pharmaceutical Co., Seoul, Korea). Bright-field microscopy images were obtained using Picture Frame software (Olympus Optical, BX51, Tokyo, Japan). Osteogenesis was evaluated by immunohistochemical staining. The specimens were reacted with a primary antibody against osteocalcin (Abcam, Cambridge, MA, USA) or bone sialoprotein (Proteintech, Rosemont, IL, USA). To quantify the extent of cellular integration into the scaffold, 2-4 fields of view (200-fold magnification) were chosen at random and analyzed by ImageJ software (Wayne Rasband, National Institute of Health, Bethesda, MD, USA) as reported previously [35].

\subsection{Statistical Analysis}

One-way analysis of variance (ANOVA) with post hoc Bonferroni test was performed between all groups, except for the analysis of the measurement by micro-CT. The MannWhitney $U$ test was used to identify statistical significances for the measurement of newly formed bone by micro-CT. In all analyses, a $p$-value $<0.05$ indicated a statistically significant difference. All statistical analyses were performed using IBM SPSS Statistics for Windows (version 23.0; IBM Corp., Armonk, NY, USA).

\section{Results}

This section is divided by subheadings. It provides a concise and precise description of the experimental results and their interpretation, as well as the conclusions that can be drawn.

\subsection{Characterization of rSVF Cells}

To investigate the surface markers of SVFs obtained from 7-week-old male SD rats, flow cytometry analysis was performed, and the results clearly demonstrated the ability of rSVF cells in passage one to differentiate under the conditions in this study. On day 1 of the culture, the rSVF cells were positive for CD29 (5\%) and CD90 (2.5\%). The cultured rSVF cells were positive for CD29 (40.8\%) and CD90 (40.3\%) by day 6 (Figure 2B). Altogether, the results demonstrated that rat SVFs had MSC-specific phenotype characteristics and possessed differentiation potential to form osteogenic lineage cells. 
A
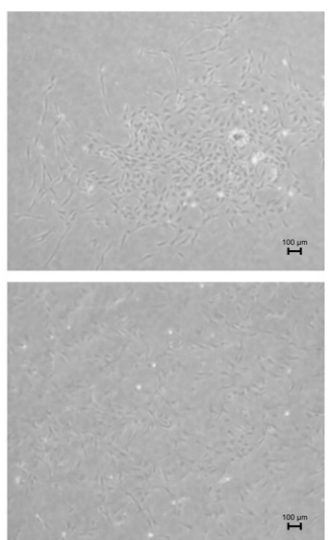

B
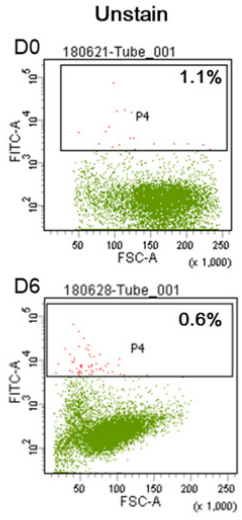
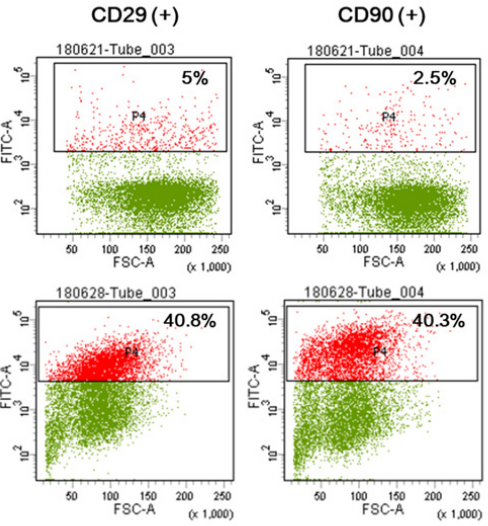

Figure 2. In vitro characterization of uncultured stromal vascular fraction cells isolated from rat adipose tissue. (A) Phase-contrast image on day 5, passage 0 and day 1, passage 1. (B) Cell surface markers CD29 and CD 90 showed the stemness of the rat stromal vascular fraction cells from day 0 , with outstanding results by day 6 . This indicates the high potential of rSVFs as an efficient source for bone differentiation. Scale bar: $100 \mu \mathrm{m}$, magnification: $\times 100$.

\subsection{Phenotype of rSVF Cells Treated with Blood Products in Osteogenic Differentiation}

During passage zero, rSVFs showed high colony-forming unit frequencies and characteristic spindle-shaped and fibroblast-like morphologies (Figure 2A). The differences between the groups were apparent after three days from treatment. Increased proliferation rate and collagen fibers were observed around the extracellular matrix in the rSVFs treated with blood products compared with the $10 \%$ FBS control. Within a week, hydroxyapatite was generated in-between rSVF cell populations. In the PPP and the FBS (control) groups, both the number and the size of mineral nodules were small. In the PRP group, the number of mineral nodules was small, but the size was about $100 \mu \mathrm{m}$. On the other hand, the degree of extracellular mineral accumulation in the WP group was significant (Figure 3).

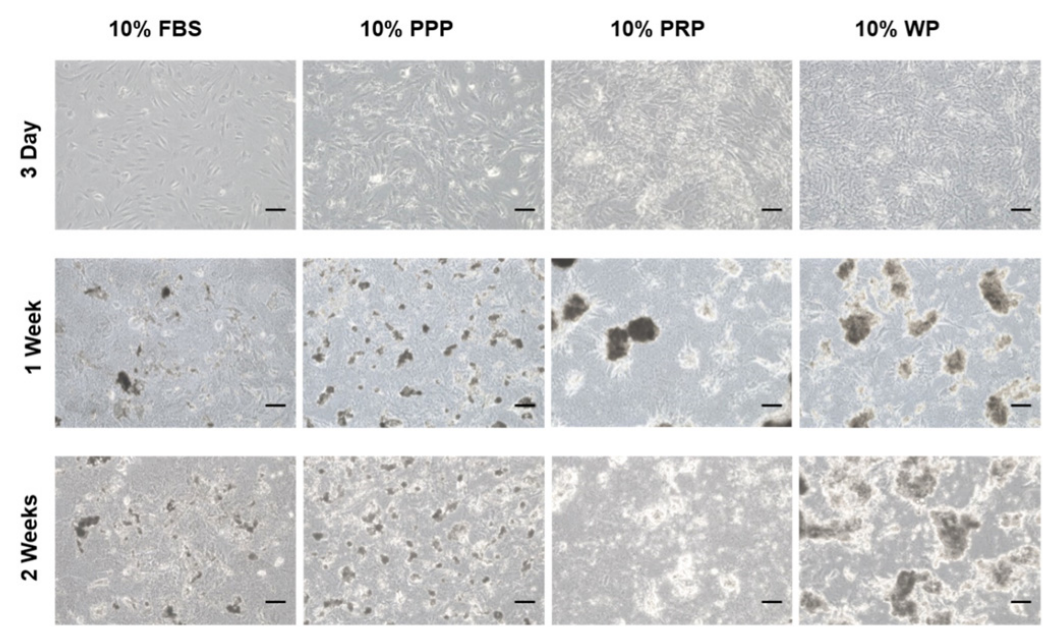

Figure 3. ECM mineralization of the cultured rSVFs at passage 1. Optical microscopic images on day 3, 1 week, and 2 weeks showed the most mineralization in the rat stromal vascular fraction cells treated with $10 \%(v / v)$ WP. PPP: platelet-poor plasma, PRP: platelet-rich plasma, WP: whole plasma, scale bar: $100 \mu \mathrm{m}$, magnification: $\times 100$.

\subsection{Semi-Quantitative Analysis of Alizarin Red S Staining}

Elongated clusters of rSVFs were collected from cell cultures which were treated with blood products ( $10 \%$ of whole volume) followed by Alizarin Red S staining (Figure S1). This anthraquinone dye staining assay was employed to follow the mineralization of 
differentiated rSVF cells and was performed 3 weeks after cell transduction, showing bright red-colored mineralized matrix in treated cells (Figure 4A). Interestingly, rSVF cells treated with WP produced significant mineralized deposits $(1.47 \pm 0.05)$ (Figure $4 \mathrm{~B})$, demonstrating that WP has a more prominent possibility of providing osteoinductive and accessible blood derivatives than PPP or PRP that require two-step centrifugations at risk of expose. As shown in Figure 4B, calcium depositions of the control ( $0.50 \pm 0.01)$, PPP $(0.78 \pm 0.01)$, and PRP $(0.51 \pm 0.01)$ groups were not as efficient.
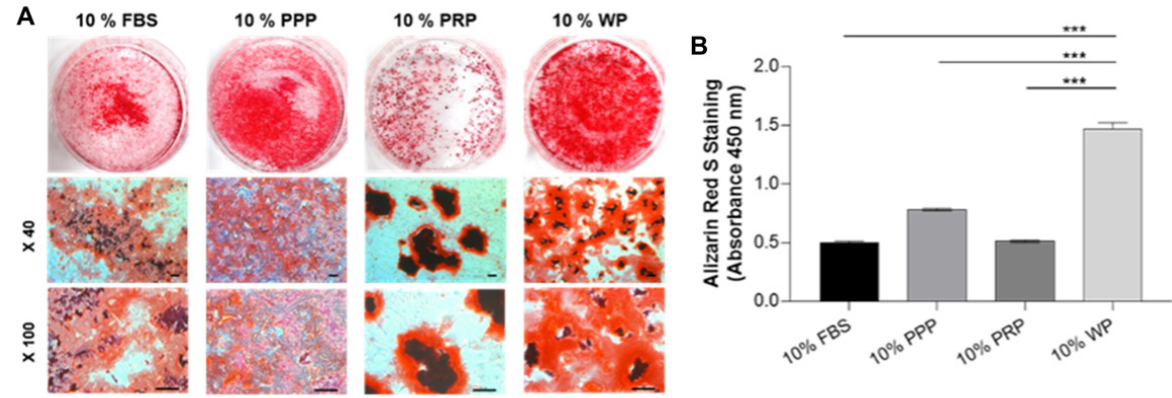

Figure 4. Semi-quantitative analysis of Alizarin Red S staining in cultured rSVFs at passage 1. (A) Optical microscopic images at 3 weeks showed the most mineralization in the SVF treated with WP and (B) quantitative results of retention of Alizarin Red S corresponding to the previous phenotype data, PPP: platelet-poor plasma, PRP: platelet-rich plasma, WP: whole plasma, scale bar: $200 \mu \mathrm{m},{ }^{* * *} p<0.001$ by Mann-Whitney $U$ test.

\subsection{Evaluation of New Bone Formation by Micro-CT}

After 7 months, based on quantitative assessment by micro-CT (Figure 5A), a significant amount of regenerated bone volume versus total volume (BT/TV) was observed in the PCL $(7.72 \% \pm 3.29)$ and the PCL scaffold + fat + WP $(6.32 \% \pm 2.06)$ groups, consistent with calcium deposit staining. In contrast, the PCL scaffold + fat $(2.15 \% \pm 0.88)$ and PCL scaffold + fat + PRP $(2.02 \% \pm 1.14)$ groups had relatively small amounts of bone formed on micro-CT images (Figure 5B).
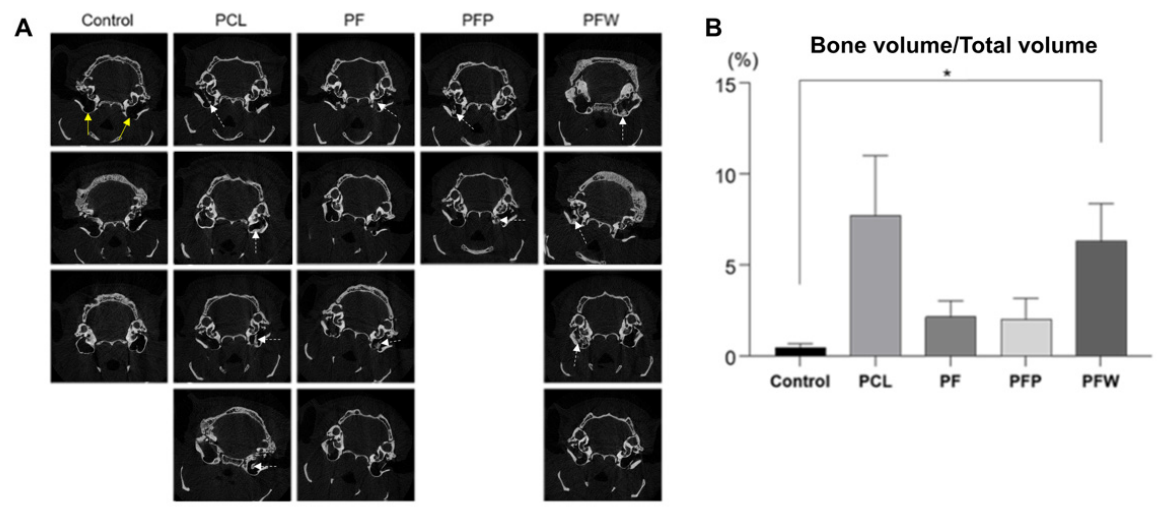

Figure 5. Measurement of newly formed bone by micro-CT. (A) After 7 months of follow up, bone tissue densities in SD rat mastoid cavities were observed by micro-CT. White dotted arrows are where the bone densities are relatively well observed. (B) The quantitative analysis of bone volume/total volume ratio represented that the PCL scaffold + fat + WP group had the highest bone volume/total volume ratio with a significant difference compared to the control group (defect). The yellow arrows indicate mastoid bulla defects. (Control group: defect only $(n=3)$; PCL group: PCL $300 \mathrm{mg}$ c $20 \mathrm{wt} \%$ without fat $(n=4) ; \mathrm{PCL}+$ fat group: PCL $300 \mathrm{mg} \mathrm{c} 20 \mathrm{wt} \%$ and fat $50 \mathrm{mg}(n=4) ; \mathrm{PCL}+\mathrm{fat}+\mathrm{PRP}$ group: PCL $300 \mathrm{mg} 20 \mathrm{wt} \%$, fat $50 \mathrm{mg}$, and PRP $50 \mathrm{uL}(n=2) ; \mathrm{PCL}+$ fat $+\mathrm{WP}$ group: PCL $300 \mathrm{mg} \mathrm{c}$ $20 \mathrm{wt} \%$, fat $50 \mathrm{mg}$, and WP $50 \mathrm{uL}(n=4))$, PRP: platelet-rich plasma, WP: whole plasma, ${ }^{*} p<0.05$ by Mann-Whitney $U$ test. 


\subsection{Evaluation of New Bone Formation by Immunohistochemistry (IHC)}

The effect of rSVF cells loaded on PCL scaffold and blood products on induced osteogenic differentiation in vivo was also evaluated by using immunohistochemical staining of bone sialoprotein and osteocalcin expressed, which are markers of osteoblasts (Figure 6A). Positive osteocalcin expression was significant in the PCL + fat + WP (PFW) group and the PCL group, $111.20( \pm 0.54)$ and $86.36( \pm 7.23)$, respectively $(p<0.005)$ (Figure $6 \mathrm{~B})$. In addition, the rSVF loaded on scaffold with and without PRP groups showed less osteogenesis; $67.73( \pm 11.68)$ and $61.00( \pm 0.765)$, respectively.

A

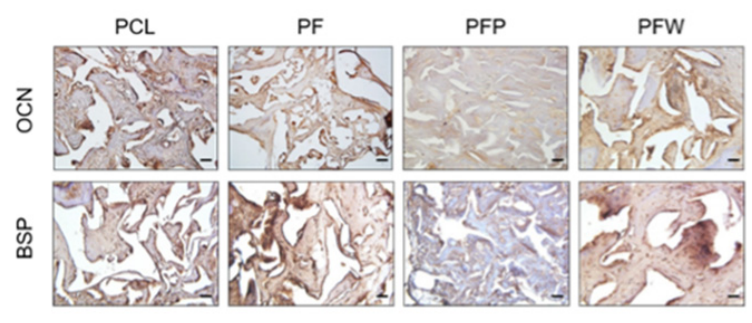

B Semi-quantification of $\mathrm{OCN}$

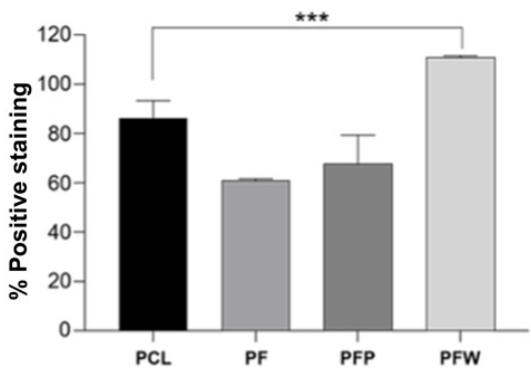

Figure 6. New bone formation of engineered PCL scaffolds at 7 months of implantation. (A) Immunohistochemical staining of osteocalcin and bone sialoprotein (DAB-hematoxylin, bright field) and (B) semi-quantification of OCN expression measured by ImageJ software. PCL group: PCL $300 \mathrm{mg}$ c $20 \mathrm{wt} \%$ neither fat nor blood products $(n=4)$; PF (PCL + fat) group: PCL $300 \mathrm{mg} \mathrm{c} 20 \mathrm{wt} \%$ and fat $50 \mathrm{mg}(n=4) ;$ PFP (PCL + fat + PRP) group: PCL $300 \mathrm{mg} 20 \mathrm{wt} \%$, fat $50 \mathrm{mg}$, and PRP $50 \mu \mathrm{L}(n=2)$; PFW (PCL + fat + WP) group: PCL $300 \mathrm{mg}$ c $20 \mathrm{wt} \%$, fat $50 \mathrm{mg}$, and WP $50 \mu \mathrm{L}(n=4))$, scale bar: $50 \mu \mathrm{m}$, magnification: $\times 200,{ }^{* * *} p<0.005$ by ANOVA and post hoc tests.

\section{Discussion}

Reconstruction of the mastoid bone defect caused by mastoidectomy is an orchestrated event. Clinically, it is necessary to accelerate bone regeneration after surgery. Conventional methods of healing temporal bone defects, such as bone grafts and grafting materials, cause severe morbidity and bone reconstruction is not always completed [36]. Therefore, this study developed a convenient and efficient one-step technique that can be performed immediately after mastoid resection by confirming bone reconstruction in the mastoid bone defect. We first showed that rSVFs can form calcium mineral nodules in three blood products: whole plasma (WP), platelet-poor plasma (PPP), and platelet-rich plasma (PRP) (Figure 3). Quantification of the degree of mineralization showed remarkably higher osteogenic differentiation with WP than with PPP or PRP (Figure 4). To investigate bone formation, micro-CT was used to assess the bone tissue in the SD rat mastoid temporal bone 7 months after surgery. Similar to the in vitro result, WP-treated rSVFs with PCL scaffold resulted in the most bone reconstruction.

Various bone tissue engineering approaches have been used to reconstruct bone. Facilitating biomaterials provide a favorable environment for bone regeneration [37]. The biological augmentation of scaffolds by cell colonization increases osteoinduction remarkably. The main purpose of using scaffolds is the retention and delivery of cells and biochemical factors for cell attachment and migration. They also serve as templates to guide the development of new tissues. Materials used for scaffolds include natural (protein-based natural biomaterials, silk, collagen, fibrin, hyaluronan, alginate, agarose, and chitosan) and synthetic (ceramics and polymers) biomaterials. Synthetic biomaterials can serve as scaffolds for culturing stem cells, control the mechanical properties and degradation rate, and can be shaped independently [38]. Ceramic scaffolds include those made of calcium sulfate, calcium phosphate, tricalcium phosphate, and hydroxyapatite. These materials do not promote osteoinduction or osteogenesis. Instead, they maintain osteoconduction by providing a structure and framework for the growing bone tissues. Calcium sulfate is 
absorbed most rapidly at 4 to 12 weeks. Hydroxyapatite is absorbed slowly and can be seen on radiographs for more than 10 years. Calcium phosphate and tricalcium phosphate are also absorbed slowly, this process taking 6 to 24 months [39-42]. Ceramic bone replacement products are very diverse, but only a few large clinical trials and randomized controlled studies have been conducted [43]. Slowly degrading polymer scaffolds are also being studied for tissue engineering. Polycaprolactone (PCL), a polyester that is resorbed slowly over 2-4 years, is a good candidate for regenerative applications. It is elastic and consists of nonpolar methylene groups and one semi-polar ester group. In tissue engineering, PCL has marked potential for bone regeneration and sufficient mechanical properties to tolerate stress loads after implantation. It is also used widely in various drug delivery applications and has obtained FDA approval for several different products [44].

Adipose tissue is a major source of multipotent stem cells in the SVF, a heterogeneous population that includes adipose-derived stem cells (ADSCs), hematopoietic cells, endothelial progenitor cells, and pericytes [45-49]. This heterogeneous pool of cells can be used in surgery, taking advantage of the immunomodulatory and pro-angiogenetic activities of the different cell populations [50-53]. ADSCs can differentiate into multiple cell types and have marked paracrine activity. However, the use of ADSCs requires additional ex vivo steps that require several days and involve a risk of exposure [54]. This limitation can be overcome by using SVF, which is readily extracted from lipoaspirates following enzymatic digestion. The heterogeneous pool cell subsets recapitulate the composition of the adipose tissue microvasculature and improve the immunomodulatory and angiogenic effects synergistically. According to reports such as the European Directive No. 4694/2007, autologous SVF is considered as an advanced therapy medicinal product that is extracted using enzyme digestion and is not intended to be used for the same essential functions in the recipient and donor [55]. Here, we tried to use autologous adipose tissue directly without enzyme treatment by obtaining a small volume of tissue during mastoidectomy and implanting it directly, minimizing external contact or any kind of manipulation. We examined whether the SVF and the ADSCs present in these adipose tissues could differentiate into bone and achieve bone regeneration.

Platelet-rich plasma is an autologous biologic containing platelets currently used in orthopedics for regenerating bone, cartilage, tendon, and ligaments. PRP is obtained from peripheral venous blood and contains many growth factors, including vascular endothelial growth factor (VEGF), platelet-derived growth factor (PDGF), and fibroblast growth factor-2 (FGF-2) [56,57]. These factors stimulate osteoblastic progenitor cell proliferation and differentiation. FGF-2 and VEGF also enhance tissue revascularization and angiogenesis [58]. Numerous studies have suggested that the use of PRP in the osteogenic environment in wounds increases osteoblast proliferation, extracellular matrix production, and fibroblastic differentiation. However, PRP preparation protocols are not standardized in terms of the growth factor release activation method, anticoagulant use, centrifugation conditions, or the volume of whole blood used, and the protocols have significantly different outcomes. For instance, anticoagulants commonly used include ethylenediaminetetraacetic acid (EDTA), sodium citrate, and acid-citrate-dextrose. The centrifugation steps can include an initial soft spin and a second hard spin with variable times and speeds. Platelets can be activated via freeze-thaw cycles to disrupt the platelet membrane and release growth factors, or exogenously using either calcium chloride or thrombin. Several researchers recommend avoiding the use of thrombin because it can result in myocardial infarction and peripheral blood clots. Moreover, bovine thrombin can cross react with human factor V leading to coagulopathies [59].

Another factor that contributes to PRP variability is the concentration of other cell types, such as leukocytes. It is debated whether leukocytes should be retained in PRP and the results of studies comparing leukocyte-rich versus pure (or leukocyte-poor) PRP are confounding. Filardo et al. reported that leukocyte-rich PRP resulted in a higher incidence of adverse effects when treating osteoarthritis than pure PRP, which had a lower leukocyte concentration [60]. Because the leukocytes in PRP are sources of pro- 
inflammatory mediators, pro-inflammatory cytokines such as interleukin- $1 \beta$ and tumor necrosis factor- $\alpha$ are activated and secreted, resulting in reduced synthesis of both COL1A1 and COL3A1 and the production of destructive proteases that inhibit extracellular matrix formation and promote its degradation. This suggests that minimizing leukocytes in PRP is more important than maximizing the platelet concentration in terms of decreasing catabolic metabolic factors and inducing matrix formation gene expression. Similarly, Oryan et al. reported that high concentrations of leukocytes in PRP appear to interfere with bone regeneration by inducing an inflammatory response that may become persistent, whereas low concentrations of leukocytes may not be able to induce the requisite inflammatory response needed in early bone regeneration [61]. Given these conflicting reports, the effect of leukocyte content on bone healing is still unclear and merits investigation. Consequently, the current study evaluated the osseous regeneration efficacy of WP obtained by a single centrifugation step for separating unneeded erythrocytes, while simultaneously retaining suitable numbers of platelets that are not excessive.

Clinically, using autologous adipose tissue and autologous WP to promote osteogenic differentiation intraoperatively are advanced therapies that do not need additional manipulations before implantation. When combined with a PCL scaffold, they had sufficient mechanical and osteoinductive properties, as in prior studies [62-69].

\section{Conclusions}

In summary, the results of this study demonstrated that the combination of rSVFs with a PCL scaffold and autologous WP can remarkably accelerate osteogenesis in a rat mastoid bone defect model. We evaluated bone formation by micro-CT imaging, Alizarin Red S staining, and immunohistochemistry. Comparing PPP, PRP, and WP, in vivo and in vitro, the whole plasma exhibited a greater ability to promote osteogenic induction. This approach represents a promising and efficient clinical technique for the anatomical and functional reconstruction of postoperative temporal bone defects following mastoidectomy.

Supplementary Materials: The following are available online at https://www.mdpi.com/article/10 .3390 / polym14050877/s1, Figure S1: The quantitative results of retention of Alizarin Red S corresponding the previous phenotypic data. Osteogenic media (OM) (-): Low glucose (1g/L) DMEM, 1\% penicillin/streptomycin with Dexamethasone $(0.1 \mu \mathrm{M}$ final $)$, L-Ascorbic acid 2-phosphate $(50.0 \mu \mathrm{M}$ final) and $\beta$-glycerophosphate (10.0 mM final). OM (+): OM with 10\% FBS, OM-P: OM with 10\% Platelet poor plasma, OM-R: OM with 10\% Platelet rich plasma, OM-WP: OM with $10 \%$ Whole plasma.

Author Contributions: Conceptualization, O.-S.C. and Y.-H.C.; methodology, S.-H.P., O.-S.C. and Y.-H.C.; formal analysis, S.-H.P. and H.K.; investigation, S.-H.P., H.K. and O.-S.C.; data curation, Y.Y.L., Y.J.K. and J.H.J.; writing—original draft preparation, S.-H.P., H.K. and O.-S.C.; writing—review and editing, H.K., O.-S.C. and Y.-H.C.; visualization, S.-H.P. and H.K.; supervision, O.-S.C. and Y.-H.C.; project administration, Y.-H.C. All authors have read and agreed to the published version of the manuscript.

Funding: This research received no external funding.

Data Availability Statement: Not applicable.

Acknowledgments: This research was supported by the Bio \& Medical Technology Development Program of the National Research Foundation (NRF) funded by the Korean government (MSIT) (NRF-2018M3A9E8023858).

Conflicts of Interest: The authors declare no conflict of interest.

\section{References}

1. Kanemaru, S.; Nakamura, T.; Omori, K.; Magrufov, A.; Yamashita, M.; Ito, J. Regeneration of mastoid air cells in clinical applications by in situ tissue engineering. Laryngoscope 2005, 115, 253-258. [CrossRef] [PubMed]

2. Ikarashi, F.; Takahashi, S.; Yamamoto, Y. Carbon dioxide exchange via the mucosa in healthy middle ear. Arch. Otolaryngol. Head Neck Surg. 1999, 125, 975-978. [CrossRef] [PubMed] 
3. Ars, B.; Wuyts, F.; Van de Heyning, P.; Miled, I.; Bogers, J.; Van Marck, E. Histomorphometric study of the normal middle ear mucosa. Preliminary results supporting the gas-exchange function in the postero-superior part of the middle ear cleft. Acta Otolaryngol. 1997, 117, 704-707. [CrossRef] [PubMed]

4. Dornhoffer, J.L. Surgical modification of the difficult mastoid cavity. Otolaryngol. Head Neck Surg. 1999, 120, 361-367. [CrossRef]

5. Mehta, R.P.; Harris, J.P. Mastoid obliteration. Otolaryngol. Clin. N. Am. 2006, 39, 1129-1142. [CrossRef]

6. Wiet, R.J.; Harvey, S.A.; Pyle, M.G. Canal wall reconstruction: A newer implantation technique. Laryngoscope 1993, 103, 594-599. [CrossRef]

7. Grote, J.J. Results of cavity reconstruction with hydroxyapatite implants after 15 years. Am. J. Otol. 1998, 19, 565-568.

8. Roberson, J.B., Jr.; Mason, T.P.; Stidham, K.R. Mastoid obliteration: Autogenous cranial bone pAte reconstruction. Otol. Neurotol. 2003, 24, 132-140. [CrossRef]

9. $\quad$ Lee, W.S.; Kim, S.H.; Lee, W.S.; Kim, S.H.; Moon, I.S.; Byeon, H.K. Canal wall reconstruction and mastoid obliteration in canal wall down tympanomastoidectomized patients. Acta Otolaryngol. 2009, 129, 955-961. [CrossRef]

10. Stricker, A.; Schramm, A.; Marukawa, E.; Lauer, G.; Schmelzeisen, R. Distraction osteogenesis and tissue engineering-new options for enhancing the implant site. Int. J. Periodontics Restor. Dent. 2003, 23, 297-302.

11. Nkenke, E.; Neukam, F.W. Autogenous bone harvesting and grafting in advanced jaw resorption: Morbidity, resorption and implant survival. Eur. J. Oral Implantol. 2014, 7 (Suppl. 2), S203-S217. [PubMed]

12. Jang, Y.; Koh, Y.G.; Choi, Y.J.; Kim, S.H.; Yoon, D.S.; Lee, M.; Lee, J.W. Characterization of adipose tissue-derived stromal vascular fraction for clinical application to cartilage regeneration. In Vitro. Cell Dev. Biol. Anim. 2015, 51, 142-150. [CrossRef] [PubMed]

13. Scherberich, A.; Galli, R.; Jaquiery, C.; Farhadi, J.; Martin, I. Three-dimensional perfusion culture of human adipose tissue-derived endothelial and osteoblastic progenitors generates osteogenic constructs with intrinsic vascularization capacity. Stem Cells 2007, 25, 1823-1829. [CrossRef] [PubMed]

14. Varma, M.J.; Breuls, R.G.; Schouten, T.E.; Jurgens, W.J.; Bontkes, H.J.; Schuurhuis, G.J.; van Ham, S.M.; van Milligen, F.J. Phenotypical and functional characterization of freshly isolated adipose tissue-derived stem cells. Stem Cells Dev. 2007, 16, 91-104. [CrossRef]

15. Bartold, M.; Gronthos, S.; Haynes, D.; Ivanovski, S. Mesenchymal stem cells and biologic factors leading to bone formation. J. Clin. Periodontol. 2019, 46 (Suppl. 21), 12-32. [CrossRef]

16. Müller, A.M.; Davenport, M.; Verrier, S.; Droeser, R.; Alini, M.; Bocelli-Tyndall, C.; Schaefer, D.J.; Martin, I.; Scherberich, A. Platelet lysate as a serum substitute for 2D static and 3D perfusion culture of stromal vascular fraction cells from human adipose tissue. Tissue Eng. Part A 2009, 15, 869-875. [CrossRef]

17. Gentile, P.; Scioli, M.G.; Bielli, A.; Orlandi, A.; Cervelli, V. Concise Review: The Use of Adipose-Derived Stromal Vascular Fraction Cells and Platelet Rich Plasma in Regenerative Plastic Surgery. Stem Cells 2017, 35, 117-134. [CrossRef]

18. Deng, C.; He, Y.; Feng, J.; Dong, Z.; Yao, Y.; Mok, H.; Lin, M.; Feng, L. Extracellular matrix/stromal vascular fraction gel conditioned medium accelerates wound healing in a murine model. Wound Repair Regen. 2017, 25, 923-932. [CrossRef]

19. Koh, Y.J.; Koh, B.I.; Kim, H.; Joo, H.J.; Jin, H.K.; Jeon, J.; Choi, C.; Lee, D.H.; Chung, J.H.; Cho, C.H.; et al. Stromal vascular fraction from adipose tissue forms profound vascular network through the dynamic reassembly of blood endothelial cells. Arterioscler. Thromb. Vasc. Biol. 2011, 31, 1141-1150. [CrossRef]

20. Rampichová, M.; Chvojka, J.; Buzgo, M.; Prosecká, E.; Mikeš, P.; Vysloužilová, L.; Tvrdík, D.; Kochová, P.; Gregor, T.; Lukáš D.; et al. Elastic three-dimensional poly ( $\varepsilon$-caprolactone) nanofibre scaffold enhances migration, proliferation and osteogenic differentiation of mesenchymal stem cells. Cell Prolif. 2013, 46, 23-37. [CrossRef]

21. Sadiasa, A.; Nguyen, T.H.; Lee, B.T. In vitro and in vivo evaluation of porous PCL-PLLA 3D polymer scaffolds fabricated via salt leaching method for bone tissue engineering applications. J. Biomater. Sci. Polym. Ed. 2014, 25, 150-167. [CrossRef]

22. Temple, J.P.; Hutton, D.L.; Hung, B.P.; Huri, P.Y.; Cook, C.A.; Kondragunta, R.; Jia, X.; Grayson, W.L. Engineering anatomically shaped vascularized bone grafts with hASCs and 3D-printed PCL scaffolds. J. Biomed. Mater. Res. A 2014, 102, 4317-4325. [CrossRef] [PubMed]

23. Sobacchi, C.; Palagano, E.; Menale, C. Bone responses to biometerials. In Handbook of Biomaterials Biocompatibility, 1st ed.; Mozafari, M., Ed.; Woodhead Publishing: Duxford, UK, 2020; Volume 1, pp. 617-636.

24. Lam, C.X.; Hutmacher, D.W.; Schantz, J.T.; Woodruff, M.A.; Teoh, S.H. Evaluation of polycaprolactone scaffold degradation for 6 months in vitro and in vivo. J. Biomed. Mater. Res. A 2009, 90, 906-919. [CrossRef] [PubMed]

25. Sun, H.; Mei, L.; Song, C.; Cui, X.; Wang, P. The in vivo degradation, absorption and excretion of PCL-based implant. Biomaterials 2006, 27, 1735-1740. [CrossRef] [PubMed]

26. Knighton, D.R.; Ciresi, K.F.; Fiegel, V.D.; Austin, L.L.; Butler, E.L. Classification and treatment of chronic nonhealing wounds Successful treatment with autologous platelet-derived wound healing factors (PDWHF). Ann. Surg. 1986, 204, 322-330. [CrossRef] [PubMed]

27. Amable, P.R.; Carias, R.B.; Teixeira, M.V.; da Cruz Pacheco, I.; Corrêa do Amaral, R.J.; Granjeiro, J.M.; Borojevic, R. Platelet-rich plasma preparation for regenerative medicine: Optimization and quantification of cytokines and growth factors. Stem Cell Res. Ther. 2013, 4, 67. [CrossRef]

28. Acebes-Huerta, A.; Arias-Fernández, T.; Bernardo, Á.; Muñoz-Turrillas, M.C.; Fernández-Fuertes, J.; Seghatchian, J.; Gutiérrez, L. Platelet-derived bio-products: Classification update, applications, concerns and new perspectives. Transfus. Apher. Sci. 2020, 59, 102716. [CrossRef] 
29. Najman, S.J.; Cvetković, V.J.; Najdanović, J.G.; Stojanović, S.; Vukelić-Nikolić, M.Đ.; Vučković, I.; Petrović, D. Ectopic osteogenic capacity of freshly isolated adipose-derived stromal vascular fraction cells supported with platelet-rich plasma: A simulation of intraoperative procedure. J. Craniomaxillofac. Surg. 2016, 44, 1750-1760. [CrossRef]

30. Mehrkens, A.; Saxer, F.; Güven, S.; Hoffmann, W.; Müller, A.M.; Jakob, M.; Weber, F.E.; Martin, I.; Scherberich, A. Intraoperative engineering of osteogenic grafts combining freshly harvested, human adipose-derived cells and physiological doses of bone morphogenetic protein-2. Eur. Cell Mater. 2012, 24, 308-319. [CrossRef]

31. Zhu, M.; Heydarkhan-Hagvall, S.; Hedrick, M.; Benhaim, P.; Zuk, P. Manual isolation of adipose-derived stem cells from human lipoaspirates. J. Vis. Exp. 2013, 79, e50585. [CrossRef]

32. Güven, S.; Mehrkens, A.; Saxer, F.; Schaefer, D.J.; Martinetti, R.; Martin, I.; Scherberich, A. Engineering of large osteogenic grafts with rapid engraftment capacity using mesenchymal and endothelial progenitors from human adipose tissue. Biomaterials 2011, 32, 5801-5809. [CrossRef]

33. Quarto, N.; Senarath-Yapa, K.; Renda, A.; Longaker, M.T. TWIST1 silencing enhances in vitro and in vivo osteogenic differentiation of human adipose-derived stem cells by triggering activation of BMP-ERK/FGF signaling and TAZ upregulation. Stem Cells $\mathbf{2 0 1 5}$ 33, 833-847. [CrossRef] [PubMed]

34. Kim, Y.J.; Park, S.G.; Shin, B.; Kim, J.; Kim, S.W.; Choo, O.S.; Yin, X.Y.; Min, B.H.; Choung, Y.H. Osteogenesis for postoperative temporal bone defects using human ear adipose-derived stromal cells and tissue engineering: An animal model study. J. Biomed. Mater. Res. A 2017, 105, 3493-3501. [CrossRef]

35. Naderi, N.; Griffin, M.F.; Mosahebi, A.; Butler, P.E.; Seifalian, A.M. Adipose derived stem cells and platelet rich plasma improve the tissue integration and angiogenesis of biodegradable scaffolds for soft tissue regeneration. Mol. Biol. Rep. 2020, 47, 2005-2013. [CrossRef] [PubMed]

36. Fishero, B.A.; Kohli, N.; Das, A.; Christophel, J.J.; Cui, Q. Current concepts of bone tissue engineering for craniofacial bone defect repair. Craniomaxillofac. Trauma Reconstr. 2015, 8, 23-30. [CrossRef] [PubMed]

37. Roseti, L.; Parisi, V.; Petretta, M.; Cavallo, C.; Desando, G.; Bartolotti, I.; Grigolo, B. Scaffolds for Bone Tissue Engineering: State of the art and new perspectives. Mater. Sci. Eng. C Mater. Biol. Appl. 2017, 78, 1246-1262. [CrossRef]

38. Haycock, J.W. 3D cell culture: A review of current approaches and techniques. Methods Mol. Biol. 2011, 695, 1-15. [CrossRef]

39. Chae, T.; Yang, H.; Leung, V.; Ko, F.; Troczynski, T. Novel biomimetic hydroxyapatite/alginate nanocomposite fibrous scaffolds for bone tissue regeneration. J. Mater. Sci. Mater. Med. 2013, 24, 1885-1894. [CrossRef]

40. Landi, E.; Tampieri, A.; Celotti, G.; Sprio, S.; Sandri, M.; Logroscino, G. Sr-substituted hydroxyapatites for osteoporotic bone replacement. Acta Biomater. 2007, 3, 961-969. [CrossRef]

41. Lerner, T.; Bullmann, V.; Schulte, T.L.; Schneider, M.; Liljenqvist, U. A level-1 pilot study to evaluate of ultraporous beta-tricalcium phosphate as a graft extender in the posterior correction of adolescent idiopathic scoliosis. Eur. Spine J. 2009, 18, 170-179. [CrossRef]

42. Finkemeier, C.G. Bone-grafting and bone-graft substitutes. J. Bone Joint Surg. Am. 2002, 84, 454-464. [CrossRef] [PubMed]

43. De Long, W.G., Jr.; Einhorn, T.A.; Koval, K.; McKee, M.; Smith, W.; Sanders, R.; Watson, T. Bone grafts and bone graft substitutes in orthopaedic trauma surgery. A critical analysis. J. Bone Joint Surg. Am. 2007, 89, 649-658. [CrossRef] [PubMed]

44. Eftekhari, H.; Jahandideh, A.; Asghari, A.; Akbarzadeh, A.; Hesaraki, S. Histopathological Evaluation of Polycaprolactone Nanocomposite Compared with Tricalcium Phosphate in Bone Healing. J. Vet. Res. 2018, 62, 385-394. [CrossRef] [PubMed]

45. Rodríguez, L.V.; Alfonso, Z.; Zhang, R.; Leung, J.; Wu, B.; Ignarro, L.J. Clonogenic multipotent stem cells in human adipose tissue differentiate into functional smooth muscle cells. Proc. Natl. Acad. Sci. USA 2006, 103, 12167-12172. [CrossRef]

46. Planat-Benard, V.; Silvestre, J.S.; Cousin, B.; André, M.; Nibbelink, M.; Tamarat, R.; Clergue, M.; Manneville, C.; Saillan-Barreau, C.; Duriez, M.; et al. Plasticity of human adipose lineage cells toward endothelial cells: Physiological and therapeutic perspectives. Circulation 2004, 109, 656-663. [CrossRef]

47. Erickson, G.R.; Gimble, J.M.; Franklin, D.M.; Rice, H.E.; Awad, H.; Guilak, F. Chondrogenic potential of adipose tissue-derived stromal cells in vitro and in vivo. Biochem. Biophys. Res. Commun. 2002, 290, 763-769. [CrossRef]

48. Shang, T.; Li, S.; Zhang, Y.; Lu, L.; Cui, L.; Guo, F.F. Hypoxia promotes differentiation of adipose-derived stem cells into endothelial cells through demethylation of ephrinB2. Stem Cell Res. Ther. 2019, 10, 133. [CrossRef]

49. Dubey, N.K.; Mishra, V.K.; Dubey, R.; Deng, Y.H.; Tsai, F.C.; Deng, W.P. Revisiting the Advances in Isolation, Characterization and Secretome of Adipose-Derived Stromal/Stem Cells. Int. J. Mol. Sci. 2018, 19, 2200. [CrossRef]

50. Kwon, H.M.; Hur, S.M.; Park, K.Y.; Kim, C.K.; Kim, Y.M.; Kim, H.S.; Shin, H.C.; Won, M.H.; Ha, K.S.; Kwon, Y.G.; et al. Multiple paracrine factors secreted by mesenchymal stem cells contribute to angiogenesis. Vascul. Pharmacol. 2014, 63, 19-28. [CrossRef]

51. Kumar, P.; Kandoi, S.; Misra, R.; Vijayalakshmi, S.; Rajagopal, K.; Verma, R.S. The mesenchymal stem cell secretome: A new paradigm towards cell-free therapeutic mode in regenerative medicine. Cytokine Growth Factor Rev. 2019, 46, 1-9. [CrossRef]

52. Madrigal, M.; Rao, K.S.; Riordan, N.H. A review of therapeutic effects of mesenchymal stem cell secretions and induction of secretory modification by different culture methods. J. Transl. Med. 2014, 12, 260. [CrossRef] [PubMed]

53. Gnecchi, M.; Danieli, P.; Malpasso, G.; Ciuffreda, M.C. Paracrine Mechanisms of Mesenchymal Stem Cells in Tissue Repair. Methods Mol. Biol. 2016, 1416, 123-146. [CrossRef] [PubMed]

54. Ferrin, I.; Beloqui, I.; Zabaleta, L.; Salcedo, J.M.; Trigueros, C.; Martin, A.G. Isolation, Culture, and Expansion of Mesenchymal Stem Cells. Methods Mol. Biol. 2017, 1590, 177-190. [CrossRef] [PubMed] 
55. Agostini, F.; Rossi, F.M.; Aldinucci, D.; Battiston, M.; Lombardi, E.; Zanolin, S.; Massarut, S.; Parodi, P.C.; Da Ponte, A.; Tessitori, G.; et al. Improved GMP compliant approach to manipulate lipoaspirates, to cryopreserve stromal vascular fraction, and to expand adipose stem cells in xeno-free media. Stem Cell Res. Ther. 2018, 9, 130. [CrossRef]

56. Alsousou, J.; Thompson, M.; Hulley, P.; Noble, A.; Willett, K. The biology of platelet-rich plasma and its application in trauma and orthopaedic surgery: A review of the literature. J. Bone Joint Surg. Br. 2009, 91, 987-996. [CrossRef]

57. King, S.M.; Reed, G.L. Development of platelet secretory granules. Semin. Cell Dev. Biol. 2002, 13, 293-302. [CrossRef]

58. Rai, B.; Oest, M.E.; Dupont, K.M.; Ho, K.H.; Teoh, S.H.; Guldberg, R.E. Combination of platelet-rich plasma with polycaprolactonetricalcium phosphate scaffolds for segmental bone defect repair. J. Biomed. Mater. Res. A 2007, 81, 888-899. [CrossRef]

59. Fernandes, G.; Yang, S. Application of platelet-rich plasma with stem cells in bone and periodontal tissue engineering. Bone Res. 2016, 4, 16036. [CrossRef]

60. Filardo, G.; Kon, E.; Pereira Ruiz, M.T.; Vaccaro, F.; Guitaldi, R.; Di Martino, A.; Cenacchi, A.; Fornasari, P.M.; Marcacci, M. Platelet-rich plasma intra-articular injections for cartilage degeneration and osteoarthritis: Single- versus double-spinning approach. Knee Surg. Sports Traumatol. Arthrosc. 2012, 20, 2082-2091. [CrossRef]

61. Oryan, A.; Alidadi, S.; Moshiri, A. Platelet-rich plasma for bone healing and regeneration. Expert Opin. Biol. Ther. 2016, 16, 213-232. [CrossRef]

62. Semyari, H.; Rajipour, M.; Sabetkish, S.; Sabetkish, N.; Abbas, F.M.; Kajbafzadeh, A.M. Evaluating the bone regeneration in calvarial defect using osteoblasts differentiated from adipose-derived mesenchymal stem cells on three different scaffolds: An animal study. Cell Tissue Bank. 2016, 17, 69-83. [CrossRef] [PubMed]

63. Carvalho, P.P.; Leonor, I.B.; Smith, B.J.; Dias, I.R.; Reis, R.L.; Gimble, J.M.; Gomes, M.E. Undifferentiated human adipose-derived stromal/stem cells loaded onto wet-spun starch-polycaprolactone scaffolds enhance bone regeneration: Nude mice calvarial defect in vivo study. J. Biomed. Mater. Res. A 2014, 102, 3102-3111. [CrossRef] [PubMed]

64. Liu, G.; Zhang, Y.; Liu, B.; Sun, J.; Li, W.; Cui, L. Bone regeneration in a canine cranial model using allogeneic adipose derived stem cells and coral scaffold. Biomaterials 2013, 34, 2655-2664. [CrossRef] [PubMed]

65. Levi, B.; James, A.W.; Nelson, E.R.; Vistnes, D.; Wu, B.; Lee, M.; Gupta, A.; Longaker, M.T. Human adipose derived stromal cells heal critical size mouse calvarial defects. PLOS ONE 2010, 5, e11177. [CrossRef]

66. Hao, W.; Pang, L.; Jiang, M.; Lv, R.; Xiong, Z.; Hu, Y.Y. Skeletal repair in rabbits using a novel biomimetic composite based on adipose-derived stem cells encapsulated in collagen I gel with PLGA-beta-TCP scaffold. J. Orthop. Res. 2010, 28, $252-257$. [CrossRef]

67. Dudas, J.R.; Marra, K.G.; Cooper, G.M.; Penascino, V.M.; Mooney, M.P.; Jiang, S.; Rubin, J.P.; Losee, J.E. The osteogenic potential of adipose-derived stem cells for the repair of rabbit calvarial defects. Ann. Plast. Surg. 2006, 56, 543-548. [CrossRef]

68. Cowan, C.M.; Shi, Y.Y.; Aalami, O.O.; Chou, Y.F.; Mari, C.; Thomas, R.; Quarto, N.; Contag, C.H.; Wu, B.; Longaker, M.T. Adipose-derived adult stromal cells heal critical-size mouse calvarial defects. Nat. Biotechnol. 2004, 22, 560-567. [CrossRef]

69. Streckbein, P.; Jäckel, S.; Malik, C.Y.; Obert, M.; Kähling, C.; Wilbrand, J.F.; Zahner, D.; Heidinger, K.; Kampschulte, M.; PonsKühnemann, J.; et al. Reconstruction of critical-size mandibular defects in immunoincompetent rats with human adipose-derived stromal cells. J. Craniomaxillofac. Surg. 2013, 41, 496-503. [CrossRef] 